NASA/TP—2013-217633

\title{
Probabilistic Analysis for Comparing Fatigue Data Based on Johnson-Weibull Parameters
}

Brian L. Vlcek

Georgia Southern University, Statesboro, Georgia

Robert C. Hendricks and Erwin V. Zaretsky

Glenn Research Center, Cleveland, Ohio 


\section{NASA STI Program . . . in Profile}

Since its founding, NASA has been dedicated to the advancement of aeronautics and space science. The NASA Scientific and Technical Information (STI) program plays a key part in helping NASA maintain this important role.

The NASA STI Program operates under the auspices of the Agency Chief Information Officer. It collects, organizes, provides for archiving, and disseminates NASA's STI. The NASA STI program provides access to the NASA Aeronautics and Space Database and its public interface, the NASA Technical Reports Server, thus providing one of the largest collections of aeronautical and space science STI in the world. Results are published in both non-NASA channels and by NASA in the NASA STI Report Series, which includes the following report types:

- TECHNICAL PUBLICATION. Reports of completed research or a major significant phase of research that present the results of NASA programs and include extensive data or theoretical analysis. Includes compilations of significant scientific and technical data and information deemed to be of continuing reference value. NASA counterpart of peer-reviewed formal professional papers but has less stringent limitations on manuscript length and extent of graphic presentations.

- TECHNICAL MEMORANDUM. Scientific and technical findings that are preliminary or of specialized interest, e.g., quick release reports, working papers, and bibliographies that contain minimal annotation. Does not contain extensive analysis.

- CONTRACTOR REPORT. Scientific and technical findings by NASA-sponsored contractors and grantees.
- CONFERENCE PUBLICATION. Collected papers from scientific and technical conferences, symposia, seminars, or other meetings sponsored or cosponsored by NASA.

- SPECIAL PUBLICATION. Scientific, technical, or historical information from NASA programs, projects, and missions, often concerned with subjects having substantial public interest.

- TECHNICAL TRANSLATION. Englishlanguage translations of foreign scientific and technical material pertinent to NASA's mission.

Specialized services also include creating custom thesauri, building customized databases, organizing and publishing research results.

For more information about the NASA STI program, see the following:

- Access the NASA STI program home page at http://www.sti.nasa.gov

- E-mail your question to help@sti.nasa.gov

- Fax your question to the NASA STI Information Desk at 443-757-5803

- Phone the NASA STI Information Desk at 443-757-5802

- Write to: STI Information Desk NASA Center for AeroSpace Information 7115 Standard Drive Hanover, MD 21076-1320 
NASA/TP_-2013-217633

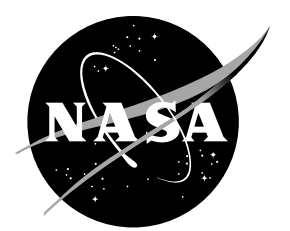

\section{Probabilistic Analysis for Comparing Fatigue Data Based on Johnson-Weibull Parameters}

Brian L. Vlcek

Georgia Southern University, Statesboro, Georgia

Robert C. Hendricks and Erwin V. Zaretsky

Glenn Research Center, Cleveland, Ohio

Prepared for the

International Design Engineering Technical Conferences and Computers and Information in Engineering Conference

sponsored by the American Society of Mechanical Engineers (ASME)

Las Vegas, Nevada, September 4-7, 2007

National Aeronautics and

Space Administration

Glenn Research Center

Cleveland, Ohio 44135 
This work was sponsored by the Fundamental Aeronautics Program at the NASA Glenn Research Center.

Level of Review: This material has been technically reviewed by expert reviewers.

Available from

NASA Center for Aerospace Information

7115 Standard Drive

Hanover, MD 21076-1320
National Technical Information Service 5301 Shawnee Road Alexandria, VA 22312

Available electronically at http://www.sti.nasa.gov 


\title{
Probabilistic Analysis for Comparing Fatigue Data Based on Johnson-Weibull Parameters
}

\author{
Brian L. Vlcek \\ Georgia Southern University \\ Statesboro, Georgia 30460 \\ Robert C. Hendricks and Erwin V. Zaretsky \\ National Aeronautics and Space Administration \\ Glenn Research Center \\ Cleveland, Ohio 44135
}

\section{Summary}

Leonard Johnson published a methodology for establishing the confidence that two populations of data are different. Johnson's methodology is dependent on limited combinations of test parameters (Weibull slope, mean life ratio, and degrees of freedom) and a set of complex mathematical equations. In this report, a simplified algebraic equation for confidence numbers is derived based on the original work of Johnson. The confidence numbers calculated with this equation are compared to those obtained graphically by Johnson. Using the ratios of mean life, the resultant values of confidence numbers at the 99 percent level deviate less than 1 percent from those of Johnson. At a 90 percent confidence level, the calculated values differ between +2 and -4 percent. The simplified equation is used to rank the experimental lives of three aluminum alloys (AL 2024, AL 6061, and AL 7075), each tested at three stress levels in rotating beam fatigue, analyzed using the Johnson-Weibull method, and compared to the ASTM Standard (E739-91) method of comparison. The ASTM Standard did not statistically distinguish between AL 6061 and AL 7075. However, it is possible to rank the fatigue lives of different materials with a reasonable degree of statistical certainty based on combined confidence numbers using the JohnsonWeibull analysis. AL 2024 was found to have the longest fatigue life, followed by AL 7075, and then AL 6061. The ASTM Standard and the Johnson-Weibull analysis result in the same stress-life exponent $p$ for each of the three aluminum alloys at the median, or $L_{50}$, lives.

\section{Introduction}

If a machine or structural component is properly designed and manufactured, a phenomenon that may limit its usable life is fatigue. Fatigue failure is not deterministic, but probabilistic. Within a given population, the variability in fatigue lives can be one or two orders of magnitude. This variability is often the result of material manufacture and use.

Fatigue is a failure mode that occurs at a stress level below the ultimate tensile stress, and is a direct result of cyclic loading. Under fatigue loading, cracks can develop at surface defects, finish marks, and inclusions (Refs. 1 and 2) or in high-stress regions of a structural body that are initially free from microscopic defects. Once cracking occurs, a dominant crack usually propagates progressively to fracture (Ref. 1).

For high-cycle components such as shafts and other highspeed rotating machinery components, the concept of a fatigue limit is employed in their design. That is, the machine element is designed where the stress to which the component is subjected is below that at which fatigue will occur. However, there are problems in defining a fatigue limit for some materials because factors such as heat treatment, surface condition, residual stresses, temperature, and environment affect fatigue life. As a further complication, aluminum and other nonferrous alloys do not exhibit a fatigue limit (Ref. 1). If an aluminum component is run long enough at any stress level it will eventually fail from fatigue.

In the real world there is always a probability that a part will fail. Instead of designing a component to never fail, machine components can be designed for a "safe" life. Hence, it becomes necessary to design for finite life with an acceptable risk or probability of failure. A knowledge and understanding of a material's fatigue life, or probability of fatigue failure, becomes essential to a good engineering design.

As a result of the expense or time associated with fatigue testing, it has been practice to analyze fatigue data based on limited sample sizes - often, 10 or fewer fatigue tests are analyzed. It is essential to maximize the information gained from a limited amount of data to ensure that data distribution is factored into the analysis. Because of a limited understanding of probabilistic failure analysis, the first inclination of most practicing engineers is to determine a statistical mean or median life. The distribution of failures or scatter in the life is not necessarily taken into account. No consideration is given to the distribution in the fatigue lives. At best, error brackets based upon the standard deviation might be considered.

If the applied stresses corresponding to the fatigue failures are known, engineers often plot the data on a stress-life $(S-N)$ curve and try to draw conclusions by comparing these curves. This would be considered as the next level in complexity of a fatigue life analysis. In general, stress-life data are analyzed according to the ASTM E739-91, "Standard Practice for Statistical Analysis of Linear or Linearized Stress-Life $(S-N)$ and Strain-Life $(\varepsilon-N)$ Fatigue Data" (Ref. 3). Unfortunately, the 
standard does not provide a method to rank the confidence that one $S-N$ curve is superior to another. At best, the standard can be used to define 95-percent confidence bands. This pair of bands brackets the linearized curve-fit and establishes limits which 95 percent of the test data would fall. The only fact that can be inferred is whether or not competing 95-percent confidence bands bracket data sets with or without overlap. If there is no overlap, it is reasonable to infer that the data sets are different from each other at a 95-percent level of confidence.

The authors of the ASTM standard (Ref. 3) recognized the inherent limitations of the standard when stating that, "As alternate fatigue models and statistical analysis are continually being developed, later revisions of this practice may subsequently present analyses that permit more complete interpretation of $S-N$ and $\varepsilon-N$ data." In fact, the ASTM standard refers to the Weibull distribution function as a possible alternative statistical analysis for such data. There are many examples in the literature of the use of the Weibull distribution function to determine the life and strength of materials, structural components, and systems/machines (Refs. 4 to 9). It is worth noting that Weibull analysis has also been used to evaluate preventative maintenance practices (Refs. 10 and 11).

Leonard G. Johnson (Ref. 12), while with the GM Research Center in the 1950s and 1960s, is credited with the first practical engineering analysis technique for evaluating fatigue data based on the Weibull distribution function. Although Johnson developed a practical method for establishing confidence that two or more populations are different, it requires difficult interpolation between or extrapolation beyond his published plots. Additionally, the mathematical technique Johnson presents is somewhat difficult to follow for someone not familiar with statistics or gamma function solutions. Finally, Johnson's work is documented in the 1964 text (Ref. 12) that is somewhat rare and difficult to find. As a result of these factors, his technique of ranking fatigue data populations based upon confidence numbers has fallen out of widespread use.

In view of the aforementioned, the objectives of the work reported herein are to (1) develop a simplified relationship to calculate confidence numbers independent of interpolation of Johnson's graphical plots, (2) develop a simplified relation to calculate confidence numbers beyond those combinations of parameters used by Johnson (Ref. 12), and (3) apply these relations to rank the experimental lives of three aluminum alloys (AL 2024, AL 6061, and AL 7075), each tested at three stress levels in rotating beam fatigue.

\section{Nomenclature}
$A_{0}$ parameter defined by Equation (3b)
$B_{0}$ parameter defined by Equation (3c)
C confidence number
$D$ parameter defined by Equation (5a)
$D O F$ total degrees of freedom

\begin{tabular}{|c|c|}
\hline$L$ & life, number of stress cycles or hr \\
\hline$L_{10}$ & $\begin{array}{l}10 \text { percent life or life at which } 90 \text { percent of a } \\
\text { population survives, number of stress cycles or hr }\end{array}$ \\
\hline$L_{50}$ & $\begin{array}{l}50 \text { percent life or life at which } 50 \text { percent of a } \\
\text { population survives, number of stress cycles of hr }\end{array}$ \\
\hline$L_{x}$ & life at which $(1-S)$ samples have failed \\
\hline$L_{\beta}$ & $\begin{array}{l}\text { characteristic life or life at which } 63.2 \text { percent } \\
\text { of population fails, number of stress cycles or } \mathrm{hr}\end{array}$ \\
\hline$m$ & Weibull slope \\
\hline$M L R$ & mean life ratio \\
\hline$M L R_{@ 99 p e r c e n t}$ & $\begin{array}{l}\text { mean life ratio at a confidence number of } \\
99 \text { percent }\end{array}$ \\
\hline$M L R \exp$ & experimental mean life ratio \\
\hline$n$ & number of data points in a data set \\
\hline$N$ & life, number of stress cycles \\
\hline$p$ & stress-life exponent \\
\hline$S$ & probability of survival, fraction or percent \\
\hline $\mathrm{Y}_{1}$ & correction parameter \\
\hline$\varepsilon$ & strain \\
\hline$\sigma$ & bending stress, $\mathrm{MPa}(\mathrm{ksi})$ \\
\hline
\end{tabular}

\section{Probabilistic Analysis Weibull Distribution Function}

Weibull (Refs. 13 to 15 ) is credited with being the first to suggest a reasonable way to estimate fracture life with a statistical distribution function. The probability distribution function empirically identified by Weibull in 1939 is as follows:

$$
\ln \ln \frac{1}{S}=m \ln \left(\frac{L_{x}}{L_{\beta}}\right) ; \quad 0<L_{x}<\infty ; 0<S<1
$$

This form is referred to as the two-parameter Weibull distribution function. Weibull empirically determined this function by fitting curves to fracture data. The variable $S$ is the level of survivability (probability of survival) being considered.

For example, if 15 percent of the samples have failed, then the survivability would be $0.85 . L_{x}$ is the life in cycles or hours at which $1-S$ percent of samples have failed. In the case of $S$ equaling 90 percent, $L_{x}$ is the life at which 10 percent of the samples have failed - this is typically referred to as the $L_{10}$ life. $L_{\beta}$ is the characteristic life of the material, which is defined as the life at which 63.2 percent of the samples have failed. Finally, $m$ is the Weibull parameter or slope, which is an indicator of the scatter or distribution in the data - the larger the number the smaller the amount of scatter. A Weibull slope of 1.0 is indicative of an exponential distribution, 2.0 is Rayleigh distribution, and 3.57 is a normal, or Gaussian, distribution of the data. 


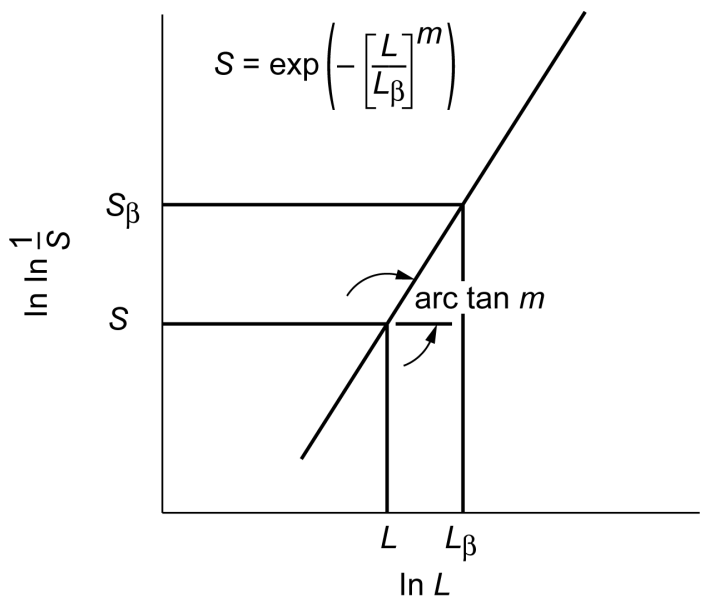

Figure 1.-Weibull plot, where $m$ is the Weibull slope or tangent of line; $S$, probability of survival; $L$, life; $L_{\beta}$, life at which 63.2 percent of population fails; and $S_{\beta}$, probability of survival of 36.8 percent at which $L=L_{\beta}$, or $L / L_{\beta}=1$.

Figure 1 is a generic Weibull plot. When plotting the $\ln \ln [1 / S]$ as the ordinate against the $\ln L$ as the abscissa, fatigue data are assumed to plot as a straight line. The ordinate $\ln \ln [1 / S]$ is graduated in statistical percent of components failed or removed for cause as a function of $\ln L$, the natural logarithm of the time or cycles to failure. The tangent of the line is designated the Weibull parameter or slope $m$, which is indicative of the shape of the cumulative distribution, or the amount of scatter of the data previously discussed.

Johnson (Ref. 12) provided the first practical engineering method for data analysis and projections using the Weibull distribution function. Effectively, a distribution of a small number of fatigue lives is ranked, plotted, and fitted with a straight line. From this Weibull plot, the life at any probability of survival can be determined.

The relative ranking of lives of competing materials can be ranked with a basic comparison of $L_{10}$ lives determined with Weibull techniques (Ref. 16). Johnson (Ref. 12) carried this concept further, by establishing confidence numbers that established the probability of whether two data sets being compared were different. These confidence numbers were dependent upon knowing the Weibull slope, total degrees of freedom, and either a mean life or $L_{10}$ life ratio.

\section{Confidence Numbers}

Johnson (Ref. 12) developed a method based on Weibull parameters for establishing the probability, which he termed "confidence number," that two values being compared were statistically different from each other. He defined the confidence number as being "the probability that the true mean life ratio of the populations is greater than unity." In other words, the reasonable statistical certainty that population $\mathrm{A}$ is better than population $\mathrm{B}$. The confidence number is calculated from a set of complex mathematical equations derived by Johnson and is a function of the degrees of freedom of the two data sets being compared, the ratio of the lives of the two data sets, and the Weibull slope $m$. Confidence numbers greater than 90 percent are considered statistically significant. This means that if the tests were to be repeated 100 times, 90 out of 100 times population A would be better than population B.

Johnson (Ref. 12) published 10 graphs based on his equations for Weibull slopes of 1.0, 1.2, 1.4, 1.6, 1.8, 2.0, 2.5, 3.0, 3.5 , and 4.0 in order to graphically determine confidence numbers. Each graph incorporates total degrees of freedom of $12,24,48,96,400$, and 3000 and mean life ratios from 1.0 to at most 3.0.

Figure 2, reproduced from Johnson (Ref. 12) for Weibull slope $m=1$, is representative of the 10 confidence number graphs. To determine the confidence number, the appropriate graph is selected based upon the Weibull slope. At the appropriate mean life ratio, the intersection with the linear curve corresponding to the desired total degrees of freedom corresponds to the confidence number.

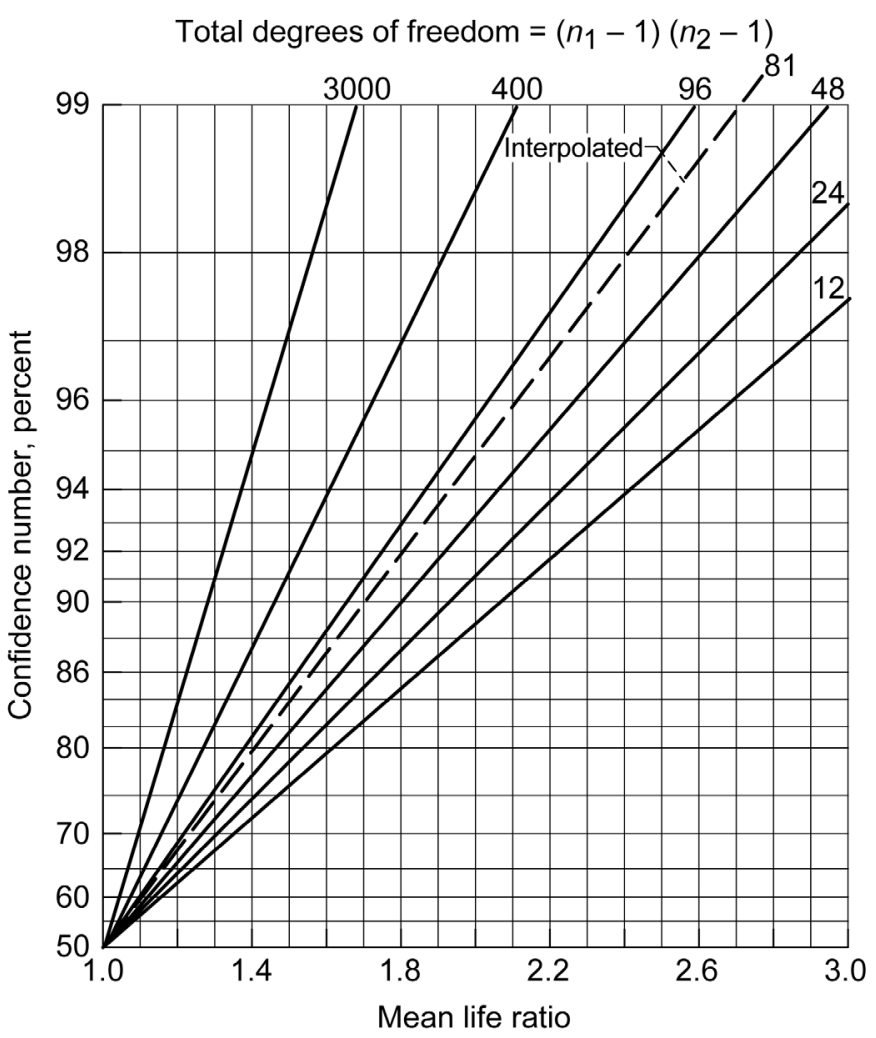

Figure 2.-Confidence numbers from Johnson (Ref.12) as a function of mean life ratio, total degrees of freedom, and Weibull slope, $m(m=1)$. 


\section{Total Degrees of Freedom}

The number of degrees of freedom is considered to be the number of parameters that may be independently varied. That is, the degree of freedom is an expression of the number of options available. For a population with a fixed mean containing $n_{i}$ failures, $\left(n_{i}-1\right)$ members can be chosen arbitrarily (Ref. 12). Once $\left(n_{i}-1\right)$ members have been selected, there is no choice of the final selection since only one member remains. Thus for this case the number of degrees of freedom is said to $\left(n_{i}-1\right)$.

When trying to rank or compare two populations, Johnson (Ref. 12) identifies the total degrees of freedom $D O F$ as

$$
D O F=\left(n_{1}-1\right)\left(n_{2}-1\right)
$$

where $n_{1}$ and $n_{2}$ are the total numbers of fatigue lives in the two data sets being compared. For example, if two data sets being compared have 10 data points each, the $D O F$ will be 81 .

Looking at each of Johnson's graphs, the limitations of the select cases for which the Johnson graphs are applicable become apparent. For example, intersection with a linear curve with a total degree of freedom of 81 requires interpolation between 48 and 96 . This interpolation for 81 degrees of freedom is shown in Figure 2. Weibull slopes that either fall between or above those for which graphs exist require interpolation between or extrapolation beyond the range covered by Johnson's graphs. Alternately, use of Johnson's mathematical solution for confidence numbers requires an understanding of Johnson's mathematical methodology. Additionally, the mathematical technique Johnson presents is somewhat difficult to follow for someone not familiar with statistics or gamma function solutions.

\section{Mean Life Ratio}

In addition to being a function of $D O F$ and Weibull slope, use of Johnson's plots require knowledge of the mean life ratio $(M L R)$ if the confidence number is to be determined. If the entire data set comprises fatigue failures (i.e., there are no suspended tests), then the mean life and average life are the same. Since Weibull distributions are generally skewed, the percentage failed or location of the mean typically differs from the 50 percent value (unless the Weibull slope is 3.57 ; i.e., a normal distribution), and decreases with increasing Weibull slope. For example, at a Weibull slope of 1.0 the mean life occurs at 63.2 percent probability of failure (36.8 percent probability of survival). For a Weibull slope of 2.0 the mean life is found at 54.4 percent probability of failure ( 45.6 percent probability of survival). Thus, care should be given since mean life and average life cannot be used interchangeably in most cases. The mean life must be determined from an appropriate Weibull analysis. When comparing two data sets, the $M L R$ is the larger of the two mean lives, divided by the smaller.

\section{Determining Mean Life Ratios at a Confidence Number of 99 Percent}

Because the limitations for the select cases for which the Johnson graphs are applicable have been established, it is desirable to have a simplified relationship for confidence number that is a function of the Weibull parameters and $D O F$. To do this, Johnson's confidence number graphs were scaled and a single mathematical equation that reproduced Johnson's linear plots was derived.

First, Johnson's 10 confidence number graphs (Ref. 12) were enlarged. The $M L R$ corresponding to a confidence number of 0.99 was read from each figure for each of the six DOF. By empirically optimizing linear parameters to minimize the percent difference between the calculated and graphically determined $M L R$ at 99 percent $\left(M L R_{@ 99 \text { percent }}\right)$, Equation (3a) was derived to provide a calculated value of $M L R_{@ 99 \text { percent: }}$ :

$$
M L R_{@ 99 \text { percent }}=\left[A_{0} \ln (D O F)+B_{0}\right]^{2}+1
$$

where

$$
A_{0}=\frac{-0.0844}{m}-0.05584
$$

and

$$
B_{0}=\frac{1.2796}{m}+0.6729
$$

where $m$ is the Weibull slope, and Equations (3b) and (3c) are functions of $m$ and used in Equation (3a). Equation (3a) fits Johnson's graphs for $1 \leq m \leq 4$ values with a deviation in $M L R$ of at most 6.5 percent with the potential for extrapolation. This calculated value of $M L R_{@ 99 \text { percent }}$ will be used in the following section to determine the confidence number-the value of ultimate interest. While $B_{0}$ is linear in $1 / m, A_{0}$ deviates somewhat from linearity in the range $2<m<3$ and is possibly better fitted as a cubic function, but then extrapolation would become highly questionable.

The intercept values of the $D O F$ locus at a confidence number of 99 percent were used to determine a calculated $M L R$ to within 6.5 percent (Eq. (3a)). For those interpolating values within the range of Johnson's figures and needing

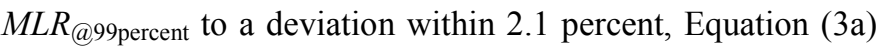
can be corrected as follows:

$$
M L R_{@ 99 \text { percent }, \text { corrected }}=\frac{M L R_{@ 99 \text { percent, fromEq.(3a) }}}{1-Y_{1}}
$$

where

$$
Y_{1}=\frac{0.5588\left[\ln (D O F)^{2}-5.8506 \ln (D O F)+12.923\right]}{100}
$$


Equation (4b) is used to calculate a constant used in Equation (4a). Equation (4a) results in a smaller percent difference between the calculated and graphically determined $M L R$, but should not be used to extrapolate values beyond the combination of Weibull parameters used by Johnson.

It is not known whether Johnson limited his design curves to the 10 slopes from 1.0 to 4.0 and 6 degrees of freedom from 12 to 3000 for technical or practical reasons. Nevertheless, Johnson does not place any limits on Weibull slope or $D O F$ when using his mathematical methodology to determine a confidence number, and there are ample examples throughout his text where he interpolates values from his figures.

\section{Simplified Expression for Confidence Numbers at Any Reasonable DOF and Weibull Slope}

Ultimately what is desired is a simplified equation that provides the confidence number $C_{i}$ at any reasonable combination of Weibull slope, $D O F$, and $M L R$. Since all of the lines of a Johnson plot pass through a point at $M L R=1.0$ and $C_{i}=0.5$, the confidence number plots in Johnson (Ref. 12) can be recreated (Fig. 2) by drawing lines through this common point and points at the intersection of the 99 percent confidence number and $M L R$ calculated using Equation (3a). These lines were fitted with an equation that minimized the deviation from the Johnson lines, and Equation (5a) is the resulting equation:

$$
C_{i}=1-0.5 \exp \left[-D\left(M L R_{\exp }-1\right)\right]
$$

where $M L R \exp$ equals the experimental $M L R$. The variable $D$ is given by Equation (5b), where

$$
\begin{aligned}
D & =\frac{\ln \left[\frac{0.5}{1-0.99}\right]}{\left(M L R_{@ 99 \text { percent }}-1\right)} \\
& =\frac{3.912}{\left(M L R_{@ 99 \text { percent }}-1\right)}
\end{aligned}
$$

where $M L R_{@ 99 \text { percent }}$ is found using Equation (3a) (or Eq. (4a) if trying to interpolate with greater accuracy). Equation (5b) is the calculation of a constant used in Equation (5a).

Equation (5a) was used to calculate the confidence for a mean life ratio's $D O F$ and Weibull slopes corresponding to confidence numbers of 99 percent as read from Johnson's 10 figures. The percent deviation of the calculated confidence number from that graphically determined is reported in Tables I through III.

The calculated values of confidence numbers in Table I differ from the graphically determined value of 0.99 by less than 1.0 percent. At a 95 percent (0.95) confidence number (Table II), the calculated value differs between +1.5 and -2.0 percent from the graphically determined value. At a 90 percent $(0.90)$ confidence number (Table III), the calculated value differs
TABLE I.-PERCENT DIFFERENCE BETWEEN THE CALCULATED CONFIDENCE NUMBER AND 0.99 CONFIDENCE NUMBER (REF. 12) FOR 10 WEIBULL SLOPES AND 6 DEGREES OF FREEDOM

\begin{tabular}{|c|c|r|r|r|r|r|}
\hline \multirow{2}{*}{$\begin{array}{c}\text { Weibull } \\
\text { slope }\end{array}$} & \multicolumn{7}{|c|}{ Degrees of freedom } \\
\hline 4.0 & 0.22 & 0.42 & 0.54 & 0.81 & 0.82 & 0.06 \\
\hline 3.5 & 0.03 & 0.25 & 0.46 & 0.59 & 0.52 & -0.03 \\
\hline 3.0 & -0.21 & 0.02 & 0.14 & 0.39 & 0.48 & 0.05 \\
\hline 2.5 & -0.41 & -0.22 & -0.04 & 0.08 & 0.32 & -0.03 \\
\hline 2.0 & -0.09 & -0.10 & -0.12 & -0.06 & -0.10 & -0.64 \\
\hline 1.8 & 0.04 & -0.04 & -0.14 & 0.03 & -0.06 & -0.56 \\
\hline 1.6 & -0.25 & -0.14 & 0.03 & 0.02 & -0.02 & -0.65 \\
\hline 1.4 & -0.24 & -0.09 & -0.05 & 0.31 & 0.18 & -0.36 \\
\hline 1.2 & -0.03 & 0.07 & 0.06 & 0.35 & 0.31 & -0.06 \\
\hline 1.0 & -0.04 & 0.09 & 0.10 & 0.35 & 0.55 & 0.05 \\
\hline
\end{tabular}

TABLE II.-PERCENT DIFFERENCE BETWEEN THE CALCULATED CONFIDENCE NUMBER AND 0.95 CONFIDENCE NUMBER (REF. 12) FOR 10 WEIBULL SLOPES AND 6 DEGREES OF FREEDOM

\begin{tabular}{|c|c|c|c|c|c|c|}
\hline \multirow{2}{*}{$\begin{array}{c}\text { Weibull } \\
\text { slope }\end{array}$} & \multicolumn{7}{|c|}{ Degrees of freedom } \\
\cline { 2 - 7 } & 12 & 24 & \multicolumn{1}{|c|}{48} & 96 & 400 & 3000 \\
\hline 4.0 & -0.24 & 0.13 & 0.54 & 0.71 & 0.49 & -1.53 \\
\hline 3.5 & -0.80 & -0.26 & -0.09 & 0.38 & 0.36 & -1.41 \\
\hline 3.0 & -1.40 & -0.99 & -0.71 & -0.32 & -0.32 & -1.66 \\
\hline 2.5 & -1.89 & -1.39 & -0.98 & -0.54 & -0.28 & -1.48 \\
\hline 2.0 & -0.55 & -0.40 & -0.50 & -0.25 & -0.39 & -2.09 \\
\hline 1.8 & -0.01 & -0.22 & -0.55 & 0.09 & -0.09 & -2.04 \\
\hline 1.6 & -0.95 & -0.49 & -0.15 & -0.17 & -0.07 & -2.37 \\
\hline 1.4 & -0.77 & -0.36 & -0.21 & 0.63 & 0.33 & -1.10 \\
\hline 1.2 & -0.09 & 0.11 & 0.08 & 0.94 & 0.78 & -0.31 \\
\hline 1.0 & -0.12 & 0.01 & 0.15 & 0.93 & 1.29 & 0.16 \\
\hline
\end{tabular}

TABLE III.-PERCENT DIFFERENCE BETWEEN THE CALCULATED CONFIDENCE NUMBER AND 0.90 CONFIDENCE NUMBER (REF. 12) FOR 10 WEIBULL SLOPES AND 6 DEGREES OF FREEDOM

\begin{tabular}{|c|c|c|c|c|c|c|}
\hline \multirow{2}{*}{$\begin{array}{c}\text { Weibull } \\
\text { slope }\end{array}$} & \multicolumn{7}{|c|}{ Degrees of freedom } \\
\hline $4 y .0$ & -1.31 & -0.80 & -0.47 & -0.27 & -0.69 & -4.08 \\
\hline 3.5 & -1.95 & -1.13 & -0.89 & -0.59 & -0.44 & -3.38 \\
\hline 3.0 & -2.37 & -1.98 & -1.87 & -1.13 & -1.56 & -3.87 \\
\hline 2.5 & -3.55 & -2.87 & -2.28 & -1.87 & -1.65 & -3.36 \\
\hline 2.0 & -1.01 & -0.62 & -0.81 & -0.57 & -0.37 & -3.34 \\
\hline 1.8 & -0.04 & -0.46 & -0.82 & -0.03 & -0.23 & -3.30 \\
\hline 1.6 & -1.53 & -0.88 & -0.36 & -0.10 & -0.25 & -4.06 \\
\hline 1.4 & -1.25 & -0.57 & -0.42 & 0.70 & 0.09 & -2.03 \\
\hline 1.2 & -0.19 & 0.17 & 0.24 & 1.25 & 1.32 & -0.27 \\
\hline 1.0 & -0.19 & 0.08 & 0.16 & 1.30 & 1.66 & -0.11 \\
\hline
\end{tabular}

between +2.0 and -4.0 percent from the graphically determined value. Thus, confidence numbers can be determined within acceptable variances using Equation (5a) for any reasonable values of $D O F$ and Weibull slope. 


\section{Combined or Composite Confidence Numbers}

When more than two related data sets are available for comparison, a composite confidence number can be calculated that incorporates significantly more data in its calculation using the following equation from Johnson (Ref. 12):

$$
C=1-2^{n-1} \prod_{i=1}^{n}\left(1-C_{i}\right)
$$

For example, if two $S-N$ curves are being compared where the fatigue life (number of cycles) is known for each of the materials at seven stresses, Equation (5a) can be used to determine the confidence number that the two lives were different at each of the seven stresses. Rather than try to interpret the significance of each of the seven confidence number values separately, each of the individual confidence numbers $\left(C_{i}\right)$ at each of the individual stress levels are incorporated into the combined confidence number using Equation (6) from Johnson (Ref. 12). For this example, $n=7$ in Equation (6).

\section{Apparatus, Specimens, and Experimental Procedure}

Experimental fatigue lives of three rotating-beam aluminum alloys (AL 2024, AL 6061, and AL 7075), were determined experimentally and initially reported in Vlcek et al. (Ref. 17). The relative fatigue lives of the three aluminum alloys are ranked herein using the simplified expression (Eq. (5a)) to determine Johnson's confidence numbers.

Fatigue lives of notched, rotating 12.7-mm- (0.5-in.-) diameter by $101-\mathrm{mm}$ - (4-in.-) long aluminum shafts (Fig. 3 ), were determined using a commercial rotational fatigue tester. This test is commonly referred to as the Krause, Budd, or Vishay fatigue test. Figure 4(a) is a sketch of the primary components of the rotational fatigue tester.

The notches in the test sample were cut on a lathe using a tungsten carbide tool insert. No surface finish or polish was performed on the cut surface. The notches were located midway $(50.8 \mathrm{~mm}$, 2 in.) along the length of the test sample (see Fig. 3). The reduced diameters of the shafts at the notches were $6.35 \mathrm{~mm}(0.25 \mathrm{in}$.), and the walls of the notch were at a $60^{\circ}$ angle.

For each test, one end of the test sample was mounted in a 12.7-mm- (0.5-in.-) diameter rotating collet. The test sample extended from the collet like a horizontal cantilever (Fig. 4 (b)). The free end was then mounted in a collet that was part of a symmetric, tapered shaft extension. The collet was rotated by a variable-speed electric motor.

A bearing from which a constant load was suspended was placed on the free end of the tapered shaft. As a result, a constant, sinusoidal load that is totally reversing each rotation of the shaft was applied to the free end of the rotating shaft. By
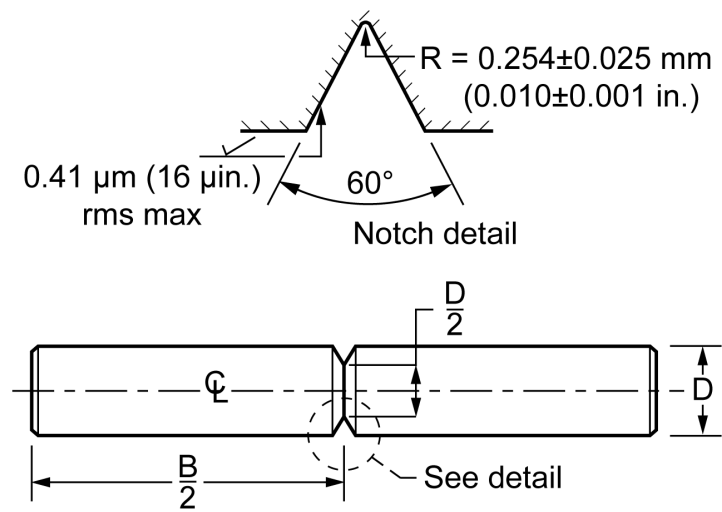

\begin{tabular}{|c|l|c|l|}
\hline Diameter D $\begin{array}{c}+0.025(0.001) \\
-0.000\end{array}$ & \multicolumn{1}{|c|}{ A } & B & C \\
\hline $6.35(0.250)$ & $15.9(0.625)$ & $51(2)$ & $19(0.75)$ \\
\hline $9.53(0.375)$ & $25(1)$ & $76(3)$ & $25(1)$ \\
\hline $12.70(0.500)$ & $31.8(1.25)$ & $102(4)$ & $38(1.5)$ \\
\hline
\end{tabular}

Dimensions are in $\mathrm{mm}$ (in.)

Figure 3.-12.7-mm (0.5-in.) aluminum alloy test sample used in rotating fatigue tester. $A$ is the collet grip length and $C$ is the exposed sample length $(C=B-2 A)$.

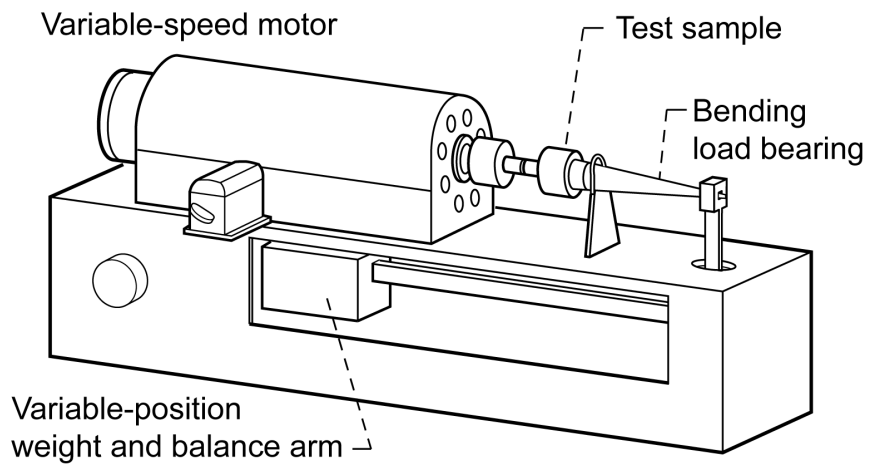

(a)

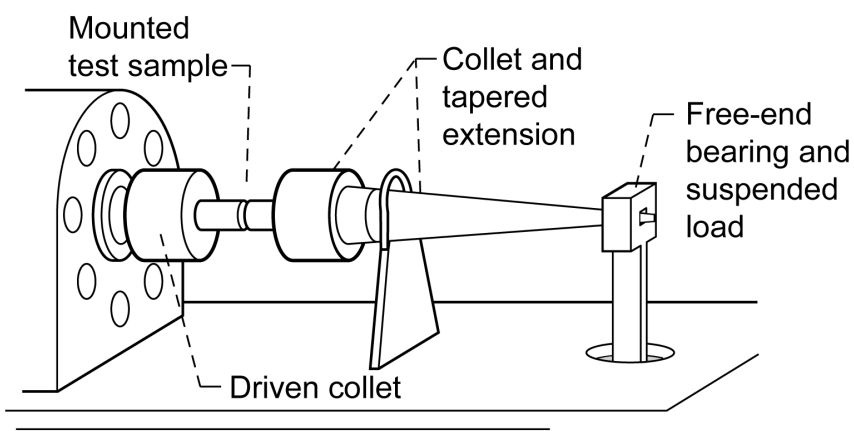

(b)

Figure 4.-Rotational bending fatigue tester. (a) Primary components. (b) Closeup of test section. 
sliding a weight along a balance arm on the apparatus, the bending stress at the minimum sample cross section can be varied from 0 to $900 \mathrm{MPa}(130.3 \mathrm{ksi})$. For this axially symmetrically loaded specimen, a fatigue crack can initiate at any point around the periphery of the shaft.

All tests were performed at room temperature and $7500 \mathrm{rpm}$. Each material was tested at three different bending stresses: 157.2, 180, and $202 \mathrm{MPa}(22.8,26.1$, and $29.3 \mathrm{ksi})$. Ten tests were conducted to failure at each stress level.

\section{Test Materials}

Three aluminum alloys, AL 2024, AL 6061, and AL 7075, were used in this study. Without alloying elements, aluminum is too soft or ductile for most engineering applications (Ref. 18).

Aluminum 2024 is used widely in the aircraft industry. At 3.8 to 4.9 percent, copper is the principal alloying element in this material. The maximum yield stress of $324 \mathrm{MPa}$ (47 ksi) and Brinell hardness of 120 were reported by the material supplier for AL 2024. It is worth noting that unprotected, this alloy does not have as good corrosion resistance as other aluminum alloys.

Aluminum 6061 is among the series of alloys that are heat treatable because of the presence of magnesium silicide. The supplier provided that the yield stress of the AL 6061 alloy was $276 \mathrm{MPa}$ (40 ksi) and the Brinell hardness was 95. While considered not as strong as other aluminum alloys, AL 6061 is one of the most versatile and widely used of the aluminum alloys because of good formability and corrosion resistance.

The major alloying element in AL 7075 is zinc at 5.1 to 6.1 percent. Magnesium, chromium, and copper are three other alloying elements found in AL 7075. With a yield stress of $503 \mathrm{MPa}(73 \mathrm{ksi})$ and a Brinell hardness of 150, AL 7075 is considered to be among the highest strength aluminum alloys.
It is used widely in the fabrication of highly stressed components, and it is a material of choice for airframes.

\section{Results and Discussions}

Rotating beam fatigue tests were carried out at three stress levels 157.2, 180, and $202 \mathrm{MPa}(22.8,26.1$, and $29.3 \mathrm{ksi})$ on three aluminum shaft alloys-AL 2024, AL 6061, and AL 7075 (Ref. 17) — and are presented in Table IV. These test results are analyzed and discussed herein.

\section{Test Results}

Figure 5 shows stress-life $(S-N)$ plots of the data of Table IV, plotted according to ASTM Standard E739-91 (Ref. 3). There is a lot of scatter in the data at each of the three stress levels. From curve fits of the life data shown in Figure 5, the median life $L_{50}$ is determined at the various stress levels. These results are summarized in Table V. From these plots, the life $L$ is inversely proportional to the stress $\sigma$ raised to the stress-life exponent $p$, where

$$
L \sim \frac{1}{\sigma^{p}}
$$

The values for stress-life exponent $p$ are shown in Figure 5(d) and summarized in Table VI.

From Figure 5, AL 2024 again has the longest fatigue life of the three alloys followed by AL 7075 and AL 6061. However, computing the 95-percent confidence bands from the ASTM standard suggests that there is no statistical significance between the lives of AL 7075 and AL 6061.

TABLE IV.-NUMBER OF STRESS CYCLES TO FAILURE AND STATISTICAL RESULTS OF 10 SAMPLES OF THREE ALUMINUM ALLOYS AT THREE BENDING STRESSES

\begin{tabular}{|c|c|c|c|c|c|c|c|c|c|}
\hline \multirow{2}{*}{$\begin{array}{l}\text { Sample } \\
\text { number }\end{array}$} & \multicolumn{3}{|c|}{ AL 2024} & \multicolumn{3}{|c|}{ AL 6061} & \multicolumn{3}{|c|}{ AL 7075} \\
\hline & $\begin{array}{c}157.2 \mathrm{MPa} \\
(22.8 \mathrm{ksi})\end{array}$ & $\begin{array}{c}180.0 \mathrm{MPa} \\
(26.1 \mathrm{ksi})\end{array}$ & $\begin{array}{c}202.0 \mathrm{MPa} \\
(29.3 \mathrm{ksi})\end{array}$ & $\begin{array}{c}157.2 \mathrm{MPa} \\
(22.8 \mathrm{ksi})\end{array}$ & $\begin{array}{c}180.0 \mathrm{MPa} \\
(26.1 \mathrm{ksi})\end{array}$ & $\begin{array}{l}202.0 \mathrm{MPa} \\
(29.3 \mathrm{ksi})\end{array}$ & $\begin{array}{c}157.2 \mathrm{MPa} \\
(22.8 \mathrm{ksi})\end{array}$ & $\begin{array}{c}180.0 \mathrm{MPa} \\
(26.1 \mathrm{ksi})\end{array}$ & $\begin{array}{c}202.0 \mathrm{MPa} \\
(29.3 \mathrm{ksi})\end{array}$ \\
\hline 1 & 142000 & 219700 & 78300 & 38900 & 16700 & 7200 & 38800 & 46100 & 21700 \\
\hline 3 & 273200 & 146600 & 113300 & 57000 & 23500 & 20800 & 51600 & 40300 & 17300 \\
\hline 4 & 188000 & 141300 & 152600 & 36400 & 17500 & 10400 & 43100 & 52300 & 24200 \\
\hline 5 & 226400 & 190500 & 135100 & 40200 & 13800 & 8600 & 64700 & 52600 & 24200 \\
\hline 8 & 204500 & 157300 & 75200 & 43100 & 27100 & 8800 & 100900 & 16800 & 10200 \\
\hline 9 & 226400 & 215500 & 68500 & 54400 & 27600 & 9600 & 47300 & 28100 & 10300 \\
\hline 10 & 203600 & 180800 & 61600 & 51400 & 32700 & 7600 & 76900 & 37300 & 10500 \\
\hline Average & 208930 & 178150 & 97500 & 57150 & 23210 & 10270 & 67590 & 38320 & 16370 \\
\hline
\end{tabular}



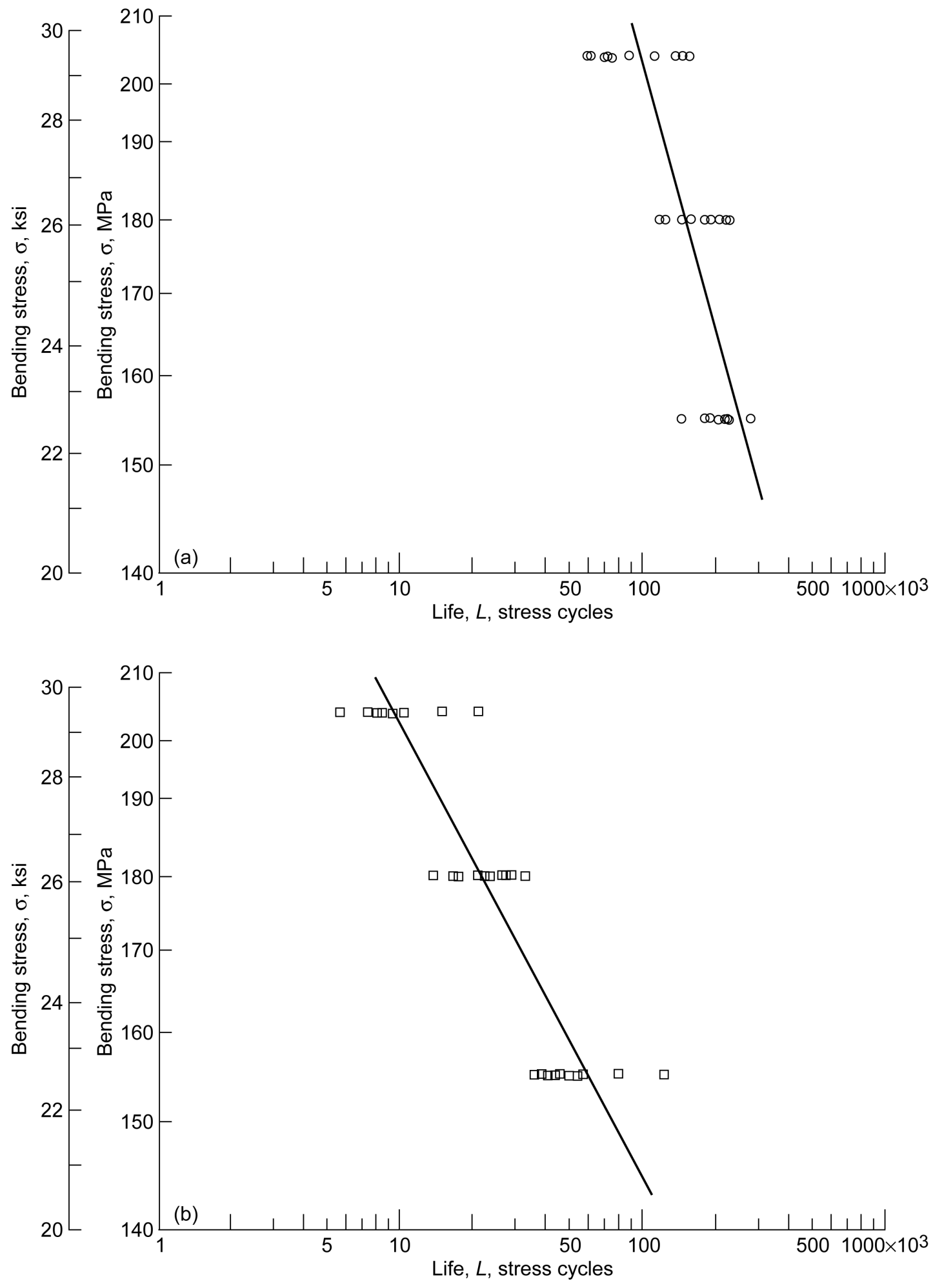

Figure 5.-Stress-life (S- $N$ ) curves for aluminum alloys in rotational bending fatigue using ASTM Standard E739-91 (2004) method. (a) AL 2024. (b) AL 6061. (c) AL 7075. (d) Summary, where $p$ is the stress-life exponent. 

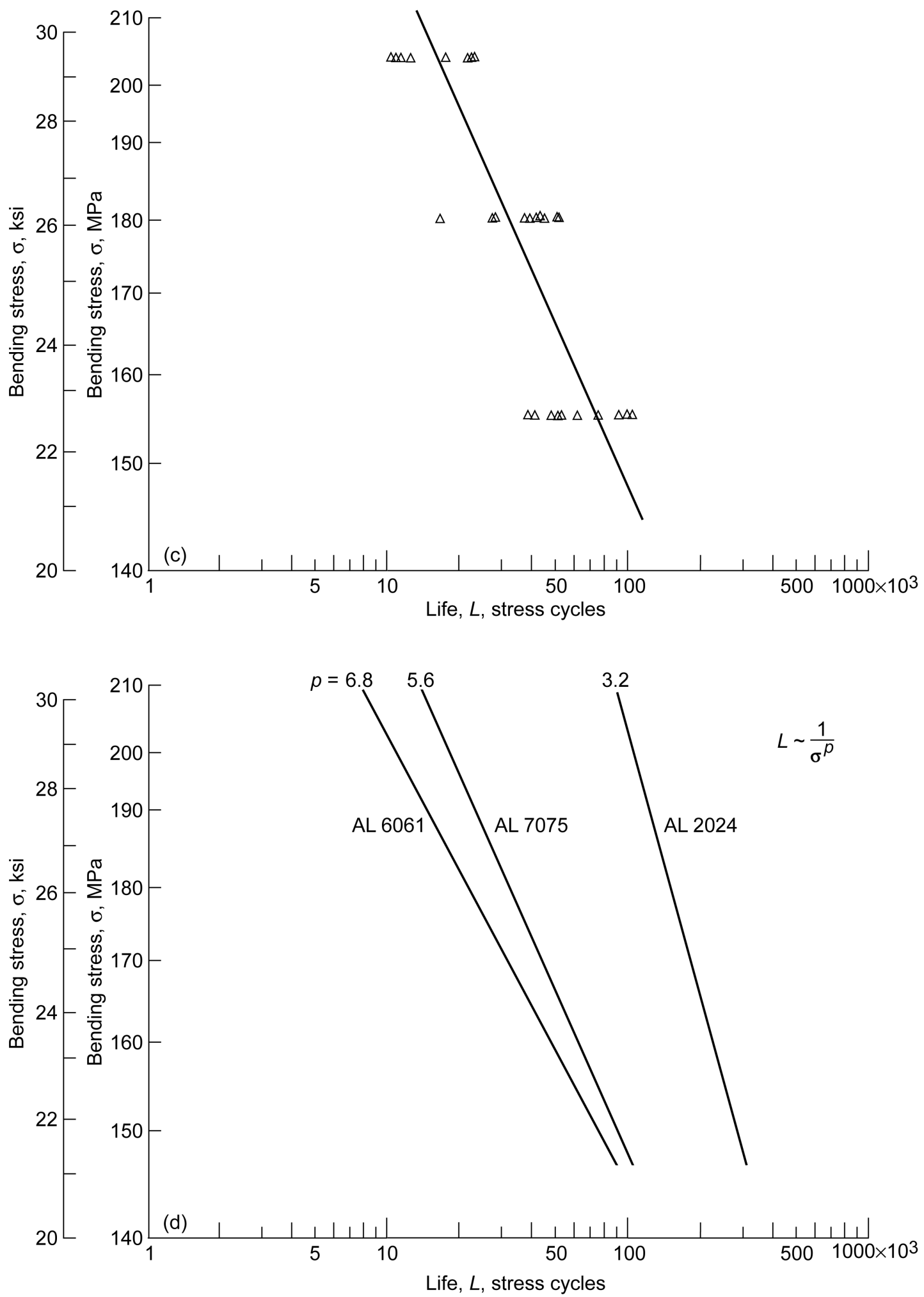

Figure 5.-Concluded. 
TABLE V.-MEDIAN LIFE

[ASTM Standard E739-91.]

\begin{tabular}{|c|c|c|c|}
\hline \multirow{2}{*}{$\begin{array}{c}\text { Stress level, } \\
\text { MPa (ksi) }\end{array}$} & \multicolumn{3}{|c|}{ Calculated life (mean life) } \\
\cline { 2 - 4 } & AL 2024 & AL 6061 & AL 7075 \\
\hline $157.2(22.8)$ & 223951 & 54147 & 67848 \\
\hline $180.0(26.1)$ & 146016 & 21567 & 31719 \\
\hline $202.0(29.3)$ & 101268 & 9811 & 16550 \\
\hline
\end{tabular}

\section{TABLE VI.-STRESS-LIFE COMPONENTS DETERMINED FOR THREE ALUMINUM ALLOYS USING FOUR DIFFERENT $S$ - $N$ CURVES}

\begin{tabular}{|c|c|c|c|}
\hline \multirow[t]{2}{*}{$S-N$ curve method } & \multicolumn{3}{|c|}{ Stress-life exponent, $p$} \\
\hline & AL 2024 & AL 6061 & AL 7075 \\
\hline ASTM standard (Fig. 5) & 3.2 & 6.8 & 5.6 \\
\hline $\begin{array}{c}\text { Johnson-Weibull } \\
\text { (Fig. 6(a)), } L_{10}\end{array}$ & 4.4 & 6.6 & 5.8 \\
\hline $\begin{array}{r}\text { Johnson-Weibull } \\
\text { (Fig. 6(b)), } L_{50}\end{array}$ & 3.1 & 6.8 & 5.6 \\
\hline
\end{tabular}

TABLE VII.-WEIBULL PARAMETERS FROM FATIGUE LIVES OF THREE ALUMINUM ALLOYS AT THREE BENDING STRESSES

[From Ref. 17.]

\begin{tabular}{|c|c|c|c|c|}
\hline Alloy & $\begin{array}{c}\text { Weibull } \\
\text { parameter }\end{array}$ & \multicolumn{3}{|c|}{ Bending stress } \\
\cline { 2 - 5 } & & $\begin{array}{c}157.2 \mathrm{MPa} \\
(22.8 \mathrm{ksi})\end{array}$ & $\begin{array}{c}180.0 \mathrm{MPa} \\
(26.1 \mathrm{ksi})\end{array}$ & $\begin{array}{c}202.0 \mathrm{MPa} \\
(29.3 \mathrm{ksi})\end{array}$ \\
\hline \multirow{4}{*}{ AL 2024 } & 6.220 & 5.122 & 2.901 \\
\cline { 2 - 5 } & Slope & 156207 & 124678 & 50701 \\
\cline { 2 - 5 } & $L_{10}$ & 211468 & 180100 & 97063 \\
\cline { 2 - 5 } & $L_{50}$ & 208503 & 177876 & 98208 \\
\cline { 2 - 5 } & Mean & 224304 & 193459 & 110136 \\
\hline \multirow{4}{*}{ Characteristic life } & \multicolumn{4}{|c|}{} \\
\hline \multirow{4}{*}{ AL 661 } & Slope & 2.549 & 4.028 & 2.747 \\
\cline { 2 - 5 } & $L_{10}$ & 26987 & 14635 & 5118 \\
\cline { 2 - 5 } & $L_{50}$ & 56510 & 23362 & 10162 \\
\cline { 2 - 5 } & Mean & 57922 & 23201 & 10333 \\
\hline \multirow{4}{*}{ Characteristic life } & 65249 & 25587 & 11612 \\
\hline & \multicolumn{3}{|c|}{} \\
\cline { 2 - 5 } & Slope & 2.894 & 3.100 & 2.640 \\
\cline { 2 - 5 } & $L_{10}$ & 35029 & 20898 & 7980 \\
\cline { 2 - 5 } & $L_{50}$ & 67160 & 38373 & 16290 \\
\cline { 2 - 5 } & Mean & 67965 & 38624 & 16631 \\
\cline { 2 - 5 } & Characteristic life & 76226 & 43189 & 18716 \\
\hline
\end{tabular}

In aerospace applications, early lives at high reliability is of primary interest and not necessarily the average or median life, even for comparison purposes. Hence, it may be reasonably concluded that where there are differences in lives that are relatively small, the ASTM method does not provide a method to differentiate with any reasonable engineering or statistical certainty whether a material is superior to another based on a fatigue criteria.

\section{Weibull Analysis}

Weibull analysis is ideally suited for determining the probable fatigue life of a larger population with a limited amount of data, and methodologies exist to rank the populations. Each data set in Table I was ranked and the Weibull parameters were determined according to Johnson (Ref. 12). These Weibull parameters are reported in Table VII. The $L_{10}$ and $L_{50}$ lives at each stress level for each material are plotted as function of stress in $S-N$ plots of Figure 6 . The stress-life exponents $p$ are given in Figure 6 and summarize in Table VI. The ASTM Standard and the Johnson-Weibull analysis result in the same stress-life exponent $p$ for each of the three aluminum alloys at the median or $L_{50}$ lives.

The ranking of the fatigue lives of AL 6061 to AL 7075, AL 6061 to AL 2024, and AL 7075 to AL 2024 was determined using Equation (5a). Then the combined confidence number, which is the probability that the 2 sets of 10 fatigue lives at each of the three stresses is different, is determined.

First, the probability that the mean life of the AL 7075 is greater than that of the AL 6061 is determined by calculating the confidence number using Equation (5a). The necessary Weibull parameters (slope and mean life ratio, $M L R$ ) can be found in Table IV. Both data sets contain 10 fatigue failures; thus the $D O F$ is still 81 . If the Weibull slopes for both sets of data were equal, only one confidence number would need to be determined. Since the AL 6061 and AL 7075 data sets have different Weibull slopes (Table VII) at a bending stress of 157.2 MPa (22.8 ksi), the confidence numbers must be determined at slopes of both 2.894 and 2.549, and then the average confidence number is calculated. From Equations (3) and (5), and Table VII with $M L R_{\exp }=67965 / 57922 \sim 1.17$, for a Weibull slope of 2.894 the confidence number is found to be 0.851 , and for a Weibull slope of 2.549 the confidence number is found to be 0.831 . The confidence number $(0.841)$ reported in Table VII is the average of these two values.

If the method is repeated at the 180.0 and 202.0 $\mathrm{MPa}(26.1$ and $29.3 \mathrm{ksi}$ ) bending stresses, the confidence numbers are found to be 0.998 and 0.992 , respectively. Thus, the life of the AL 7075 aluminum is greater than that of the AL 6061 at 180.0 and $202.0 \mathrm{MPa}(26.1$ and $29.3 \mathrm{ksi}$ ) with greater than a 99 percent confidence. However, the difference in the fatigue lives of the two materials at 157.2 $\mathrm{MPa}(22.8 \mathrm{ksi})$ are not statistically significant, with an 84 percent confidence.

Since multiple related data sets are available, a combined or composite confidence number can be determined. According to Johnson (Ref. 12), a "composite" or combined confidence number $C$ can be determined that incorporates and compares all data sets (six in this case).

Substituting in the values of $C_{i}$ at the three bending stresses (0.831, 0.998, and 0.992) and solving for $C$ using Equation (6) where in this case $n=3$, 

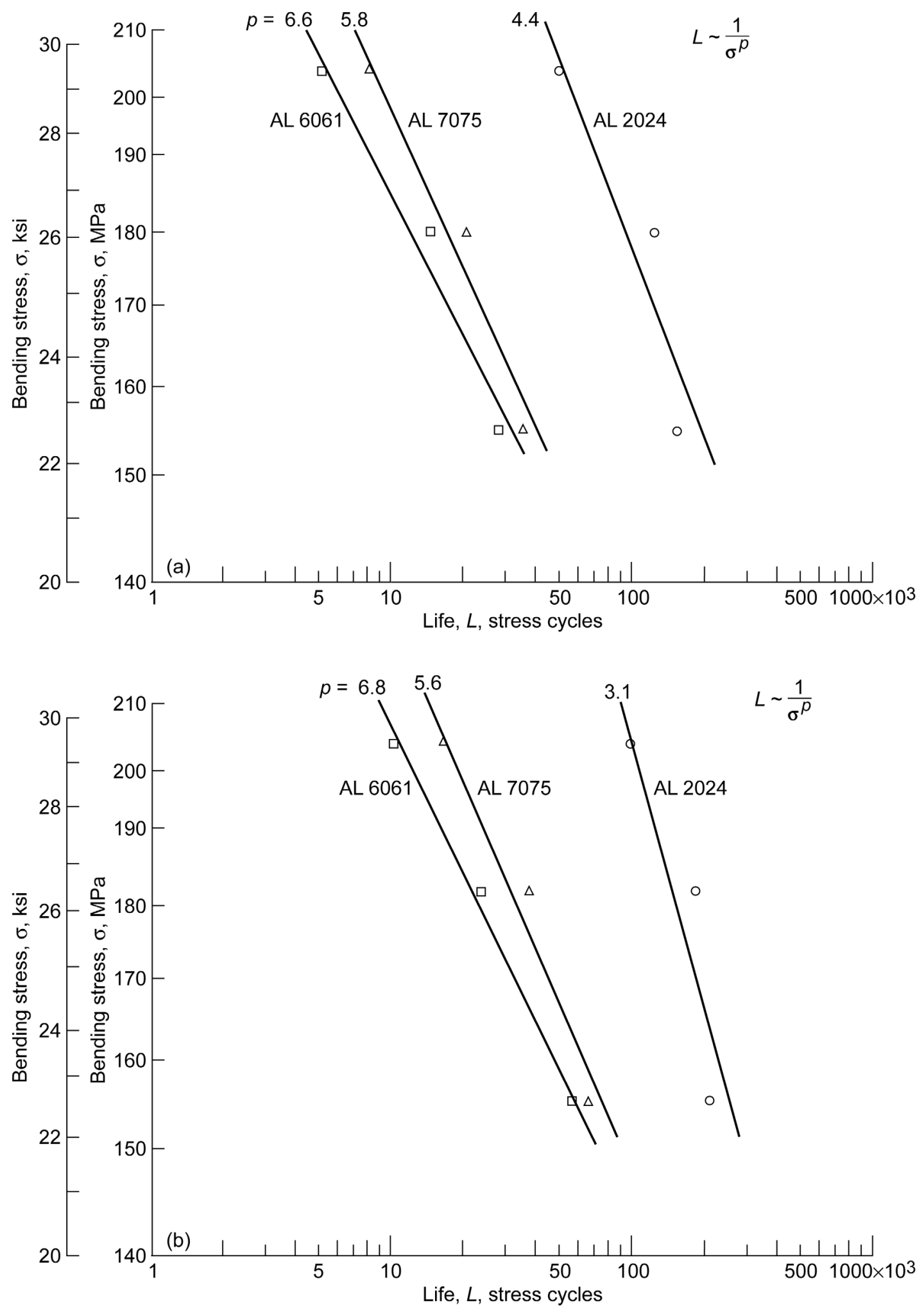

Figure 6.-Stress-life (S-N) curves for aluminum alloys AL 2024, AL 6061, and AL 7075 in rotational bending fatigue using Johnson-Weibull analysis, where $p$ is the stress-life exponent. (a) 10-percent lives, $L_{10}$. (b) 50 -percent (median) lives, $L_{50}$. 
TABLE VIII.-CALCULATED CONFIDENCE NUMBERS FOR THREE ALUMINUM ALLOYS AT THREE BENDING STRESSES

\begin{tabular}{|c|c|c|c|c|c|c|c|}
\hline \multirow{2}{*}{$\begin{array}{l}\text { Bending stress, } \\
\text { MPa (ksi) }\end{array}$} & \multirow{2}{*}{$\begin{array}{l}\text { Aluminum alloys } \\
\text { compared }\end{array}$} & \multirow{2}{*}{$\begin{array}{l}\text { Mean } \\
\text { life } \\
\text { ratio }\end{array}$} & \multicolumn{3}{|c|}{ Weibull slope } & \multirow{2}{*}{$\begin{array}{l}\text { Degrees of } \\
\text { freedom }\end{array}$} & \multirow{2}{*}{$\begin{array}{c}\text { Calculated } \\
\text { confidence } \\
\text { number }\end{array}$} \\
\hline & & & $m_{\mathrm{AL} 7075}$ & $m_{\mathrm{AL} 6061}$ & $m_{\mathrm{AL} 2024}$ & & \\
\hline 157.2 & AL 6061 and AL 7075 & 1.17 & 2.894 & 2.549 & ------ & 81 & 0.841 \\
\hline 180.0 & AL 6061 and AL 7075 & 1.66 & 3.10 & 4.028 & $\begin{array}{ll}----- \\
\end{array}$ & 81 & 0.998 \\
\hline 202.0 & AL 6061 and AL 7075 & 1.61 & 2.64 & 2.747 & $\begin{array}{ll}----- \\
-\cdots\end{array}$ & 81 & 0.992 \\
\hline 157.2 & AL 6061 and AL 2024 & 3.60 & ------ & 2.549 & 6.220 & 81 & 0.999 \\
\hline 180.0 & AL 6061 and AL 2024 & 7.67 & $\begin{array}{ll}---- \\
-\end{array}$ & 4.028 & 5.122 & 81 & 0.999 \\
\hline 202.0 & AL 6061 and AL 2024 & 9.50 & ------ & 2.747 & 2.901 & 81 & 0.999 \\
\hline 157.2 & AL 7075 and AL 2024 & 3.07 & 2.894 & ------ & 6.220 & 81 & 0.999 \\
\hline 180.0 & AL 7075 and AL 2024 & 4.61 & 3.10 & $\begin{array}{l}----- \\
--\end{array}$ & 5.122 & 81 & 0.999 \\
\hline 202.0 & AL 7075 and AL 2024 & 5.91 & 2.64 & ------ & 2.901 & 81 & 0.999 \\
\hline
\end{tabular}

$$
\begin{aligned}
C & =1-2^{(3-1)}(1-0.831)(1-0.998)(1-0.992) \\
& =0.999989
\end{aligned}
$$

As a result of incorporating two-thirds more data, greater confidence is achieved in stating that one material is longer lived than another at these test conditions. In this case, the AL 7075 is longer lived than the AL 6061.

The process is repeated to rank AL 2024 and AL 7075 and rank AL 2024 and AL 6061 by determining the probability and comparing the $M L R$ of each. The individual confidence numbers for both of these comparisons at each of three bending stresses are reported in Table VIII. The combined confidence number in both of these cases is significantly greater than 0.99. The AL 7075 mean fatigue life is greater than that of AL 6061 with a probability more than 99 percent. The fatigue life of the AL 2024 is greater than both the AL 7075 and AL 6061 with a probability or more than 99 percent. It is thus possible to rank the fatigue lives of different materials with a reasonable degree of statistical certainty.

\section{Summary of Results}

Probabilistic failure analysis is essential when analysis of $S-N$ curves is inconclusive in determining the relative ranking of two or more materials. In 1964, Leonard Johnson published a methodology for establishing the confidence that two populations of data are different. Johnson's methodology is dependent on a limited combination of test parameters (Weibull slope, mean life ratio, and degrees of freedom) and a set of complex mathematical equations. To create a simplified method, Johnson's original confidence number plots were fitted, and an equation was found for confidence number as a function of Weibull slope, degree of freedom, and mean life ratio. The confidence numbers calculated with this equation were compared to those obtained graphically from Johnson. The simplified equation was used to rank the experimental lives of three aluminum alloys (AL 2024, AL 6061, and AL 7075), each tested at three stress levels in rotating beam fatigue analyzed using the Johnson-Weibull method and compared to the
ASTM Standard (E739-91) method of comparison. The following results were obtained:

1. Using the ratios of mean life, the resultant values of confidence numbers at 99 percent deviated less than 1 percent from those of Johnson using the simplified algebraic equation. At a 90 percent (0.90) confidence number, the calculated values differed between +2 and -4 percent.

2. The ASTM Standard (E739-91) method did not statistically distinguish between AL 6061 and AL 7075. However, it is possible to rank the fatigue lives of different materials with a reasonable degree of statistical certainty based on combined confidence numbers using JohnsonWeibull analysis. AL 2024 was found to have the longest fatigue life, followed by AL 7075, and then AL 6061.

3. The ASTM Standard and the Johnson-Weibull analysis result in the same stress-life exponent $p$ for each of the three aluminum alloys at the median or $L_{50}$ lives.

Glenn Research Center

National Aeronautics and Space Administration

Cleveland, Ohio, April 29, 2013

\section{References}

1. Tipton, S.M.: Static and Fatigue Design. Mechanical Design Handbook, Harold A. Rothbart, ed., McGraw-Hill, New York, NY, sec. 7, 1996, pp. 7.3-7.73.

2. Zaretsky, E.V.: STLE Life Factors for Rolling Bearings. STLE SP-34, 1992.

3. Standard Practice for Statistical Analysis of Linear or Linearized Stress-Life $(\boldsymbol{S}-\boldsymbol{N})$ and Strain-Life $(\boldsymbol{\varepsilon}-\boldsymbol{N})$ Fatigue Data. Active Standard E739-91, vol. 03.01, ASTM International, 2004.

4. Burrow, M.F. et al.: Analysis of Tensile Bond Strengths Using Weibull Statistics. Biomaterials, vol 25, no. 20, 2004, pp. 5031-5035.

5. Ellis, F.V.; and Tordonato, S.: Failure Analysis and Life Assessment Studies for Boiler Tubes. ASME Pressure Vessels and Piping Division Publication, vol. 392, 1999, pp. 3-13.

6. Tomimatsu, M.; Sakai, M.; and Kikuchi, M.: Fracture Toughness Evaluation Based on the Master Curve Procedure. ASME Pressure Vessels and Piping Division Publication, 1997, pp. 343-348. 
7. Osborne, Nora; Graves, George G.; and Ferber, Matt K.: Dynamic Fatigue Testing of Candidate Ceramic Materials for Turbine Engines to Determine Slow-Crack-Growth Parameters. ASME Paper, 1995.

8. Ostojic, P.; and Berndt, C.C.: Variability in Strength of Thermally Sprayed Coatings. Surf. Coat. Technol., vol. 34, no. 1, 1987, pp. $43-50$.

9. Holland, F.A.; and Zaretsky, E.V.: Investigation of Weibull Statistics in Fracture-Analysis of Cast-Aluminum. J. Mech. Des., vol. 112, no. 2, 1990, pp. 246-254.

10. Williams, Samuel R.; and Fec, Michael C.: Weibull Analysis of Reconditioned Railroad Roller Bearing Life Test Data. ASME Rail Transportation Division Publication, vol. 5, 1992, pp. 83-87.

11. Summers-Smith, J.D.: Fault Diagnosis as an Aid to Process Machine Reliability. Quality and Reliability Engineering International, vol 5, no 3, 1989, pp. 203-205.

12. Johnson, L.G.: The Statistical Treatment of Fatigue Experiments. Elsevier Publishing Co., Amsterdam, The Netherlands, 1964.
13. Weibull, W.: A Statistical Theory of the Strength of Materials. Ingenioersvetenskapsakad. Handl., no. 151, Stockholm, Sweden, 1939.

14. Weibull, W.: The Phenomenon of Rupture in Solids. Ingenioersvetenskapsakad. Handl., no. 153, Stockholm, Sweden, 1939.

15. Weibull, W.: A Statistical Distribution Function of Wide Applicability. J. Appl. Mech. Trans. ASME, vol. 18, no. 3, 1951, pp. 293-297.

16. Vlcek, B.L.; Hendricks, R.C.; and Zaretsky, E.V.: Comparative Fatigue Lives of Rubber and PVC Wiper Cylindrical Coatings. Trib. Trans., vol. 46, no. 1, 2003, pp. 101-110.

17. Vlcek, B.L., et al.: Experimental Determination of Fatigue Lives of Rotating Aluminum Alloys Using Weibull Analysis. 125ISROMAC-11, Paper presented at the 11th International Symposium on Transport Phenomena and Dynamics of Rotating Machinery Honolulu, HI, 2006.

18. Aluminum Standards and Data. Sixth ed., Aluminum Association, Washington, DC, 1979. 


\begin{tabular}{|c|c|c|c|c|c|}
\hline \multicolumn{5}{|c|}{ REPORT DOCUMENTATION PAGE } & $\begin{array}{c}\text { Form Approved } \\
\text { OMB No. 0704-0188 }\end{array}$ \\
\hline \multicolumn{6}{|c|}{ 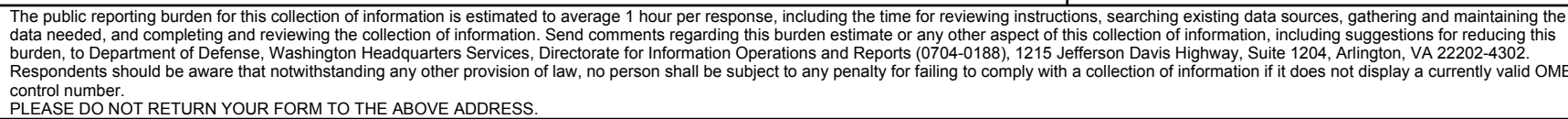 } \\
\hline \multicolumn{2}{|c|}{$\begin{array}{l}\text { 1. REPORT DATE (DD-MM-YYYY) } \\
01-04-2013\end{array}$} & \multicolumn{3}{|c|}{$\begin{array}{l}\text { 2. REPORT TYPE } \\
\text { Technical Paper }\end{array}$} & 3. DATES COVERED (From - To) \\
\hline \multirow{3}{*}{\multicolumn{5}{|c|}{$\begin{array}{l}\text { 4. TITLE AND SUBTITLE } \\
\text { Probabilistic Analysis for Comparing Fatigue Data Based on Johnson-Weibull Parameters }\end{array}$}} & 5a. CONTRACT NUMBER \\
\hline & & & & & 5b. GRANT NUMBER \\
\hline & & & & & 5c. PROGRAM ELEMENT NUMBER \\
\hline \multirow{3}{*}{\multicolumn{5}{|c|}{$\begin{array}{l}\text { 6. AUTHOR(S) } \\
\text { Vlcek, Brian, L.; Hendricks, Robert, C.; Zaretsky, Erwin, V. }\end{array}$}} & 5d. PROJECT NUMBER \\
\hline & & & & & 5e. TASK NUMBER \\
\hline & & & & & $\begin{array}{l}\text { 5f. WORK UNIT NUMBER } \\
\text { WBS 561581.02.07.03 }\end{array}$ \\
\hline \multicolumn{5}{|c|}{$\begin{array}{l}\text { 7. PERFORMING ORGANIZATION NAME(S) AND ADDRESS(ES) } \\
\text { National Aeronautics and Space Administration } \\
\text { John H. Glenn Research Center at Lewis Field } \\
\text { Cleveland, Ohio } 44135-3191\end{array}$} & $\begin{array}{l}\text { 8. PERFORMING ORGANIZATION } \\
\text { REPORT NUMBER } \\
\text { E-16056-2 }\end{array}$ \\
\hline \multirow{2}{*}{\multicolumn{5}{|c|}{$\begin{array}{l}\text { 9. SPONSORING/MONITORING AGENCY NAME(S) AND ADDRESS(ES) } \\
\text { National Aeronautics and Space Administration } \\
\text { Washington, DC 20546-0001 }\end{array}$}} & $\begin{array}{l}\text { 10. SPONSORING/MONITOR'S } \\
\text { ACRONYM(S) } \\
\text { NASA }\end{array}$ \\
\hline & & & & & $\begin{array}{l}\text { 11. SPONSORING/MONITORING } \\
\text { REPORT NUMBER } \\
\text { NASA/TP-2013-217633 }\end{array}$ \\
\hline \multicolumn{6}{|c|}{$\begin{array}{l}\text { 12. DISTRIBUTION/AVAILABILITY STATEMENT } \\
\text { Unclassified-Unlimited } \\
\text { Subject Category: } 37 \\
\text { Available electronically at http://www.sti.nasa.gov } \\
\text { This publication is available from the NASA Center for AeroSpace Information, 443-757-5802 }\end{array}$} \\
\hline \multicolumn{6}{|c|}{$\begin{array}{l}\text { 13. SUPPLEMENTARY NOTES } \\
\text { Erwin V. Zaretsky is currently a Distinguished Research Associate. }\end{array}$} \\
\hline \multicolumn{6}{|c|}{$\begin{array}{l}\text { 14. ABSTRACT } \\
\text { L. Johnson published a methodology for establishing the confidence that two populations of data are different. Johnson's methodology is } \\
\text { dependent on limited combinations of test parameters (Weibull slope, mean life ratio, and degrees of freedom) and a set of complex } \\
\text { mathematical equations. In this report, a simplified algebraic equation for confidence numbers is derived based on the original work of L. } \\
\text { Johnson. The confidence numbers calculated with this equation are compared to those obtained graphically by Johnson. Using the ratios of } \\
\text { mean life, the resultant values of confidence numbers at the } 99 \text { percent level deviate less than } 1 \text { percent from those of Johnson. At a } 90 \\
\text { percent confidence level, the calculated values differ between }+2 \text { and }-4 \text { percent. The simplified equation is used to rank the experimental } \\
\text { lives of three aluminum alloys (AL } 2024 \text {, AL } 6061 \text {, and AL } 7075 \text { ), each tested at three stress levels in rotating beam fatigue, analyzed using } \\
\text { the Johnson-Weibull method, and compared to the ASTM Standard (E739-91) method of comparison. The ASTM Standard did not } \\
\text { statistically distinguish between AL } 6061 \text { and AL } 7075 \text {. However, it is possible to rank the fatigue lives of different materials with a } \\
\text { reasonable degree of statistical certainty based on combined confidence numbers using the Johnson-Weibull analysis. AL } 2024 \text { was found to } \\
\text { have the longest fatigue life, followed by AL 7075, and then AL } 6061 \text {. The ASTM Standard and the Johnson-Weibull analysis result in the } \\
\text { same stress-life exponent p for each of the three aluminum alloys at the median, or L50, lives. }\end{array}$} \\
\hline \multicolumn{6}{|c|}{$\begin{array}{l}\text { 15. SUBJECT TERMS } \\
\text { Probabilistic life prediction; Rolling-element bearings; Bearing life prediction; Weibull analysis }\end{array}$} \\
\hline \multicolumn{3}{|c|}{ 16. SECURITY CLASSIFICATION OF: } & $\begin{array}{l}\text { 17. LIMITATION OF } \\
\text { ABSTRACT }\end{array}$ & $\begin{array}{l}\text { 18. NUMBER } \\
\text { OF }\end{array}$ & $\begin{array}{l}\text { 19a. NAME OF RESPONSIBLE PERSON } \\
\text { STI Help Desk (email:help@sti.nasa.gov) }\end{array}$ \\
\hline $\begin{array}{l}\text { a. REPORT } \\
\text { U }\end{array}$ & $\begin{array}{l}\text { b. ABSTRACT } \\
\text { U }\end{array}$ & $\begin{array}{l}\text { c. THIS } \\
\text { PAGE } \\
\text { U }\end{array}$ & UU & $\begin{array}{c}\text { PAGES } \\
20\end{array}$ & $\begin{array}{l}\text { 19b. TELEPHONE NUMBER (include area code) } \\
443-757-5802\end{array}$ \\
\hline
\end{tabular}



